\title{
Teoría del Estado
}

Theory of the State

Teoria do Estado

\section{Horacio González}

UNIVERSIDAD DE BUENOS AIRES, ARGENTINA

Profesor Titular de la Universidad de Buenos Aires. Doctor en Ciencias

Sociales de la Universidad de São Paulo, Brasil. Desde 2005 se

desempeña como director de la Biblioteca Nacional de Argentina.

Entre sus últimas publicaciones se encuentran: El acorazado

Potemkin en los mares argentinos (Colihue, 2010), Kirchnerismo, una controversia cultural (Colihue, 2011), Genealogías. Violencia

y trabajo en la historia argentina (Homo Sapiens-Facultad Libre, 2011), Lengua del ultraje. De la generación del 37 a David Viñas

(Colihue, 2012). Correo electrónico: direccion@bn.gov.ar

\section{Ensayo}

Publicado originalmente en Página/12, junio de 2014.

Documento accesible en línea desde la siguiente dirección: http://revistas.javeriana.edu.co

doi:10.11144/Javeriana.CL19-37.tdes

\section{Cómo citar este ensayo:}

González, Horacio. "Teoría del Estado". Cuadernos de Literatura 19.

37 (2015): 17-19. doi:10.11144/Javeriana.CL19-37.tdes 
SE PRECISA UNA nueva teoría del Estado. En vez de temer que el Estado, al ocuparse de reactivar los núcleos del pensamiento emancipador existente en toda sociedad, se proyecte inhibitoriamente sobre ellos, debe pensarse en la adquisición de dimensiones libertarias por parte del Estado. Un Estado libertario y justo. Ni un Estado empresario, ni un Estado ausente, ni un Estado omnipotente, ni un Estado sin políticas colectivas, ni un Estado regulador de la cultura, ni un Estado sin competencias sobre la producción social y las políticas efectivas de soberanía en la acción política y económica. En verdad, un Estado amasado en libertades objetivas y subjetivas es lo que merece la época, y desde luego la multivariada y heterogénea cultura social argentina. La reciente creación de una secretaría de Estado vinculada con la promoción cultural, con el nombre de "coordinación estratégica", despertó suspicacias que quien ocupará el cargo, Ricardo Forster, se ocupó de disipar adecuadamente con solo recordar su currículum y su formación humanística fundada en el alto pensamiento crítico de raíz universalista.

Efectivamente no es afortunado el nombre, pero podrá ser fructífera la función, entendiéndola de una manera original, porque en su intención profunda es un llamado a la invención cultural. Proponemos entonces la noción de Estado libertario, máxima condensación intelectual de una época compleja, capaz de hacer aparecer la noción de autonomía crítica - la célebre autopoiesis de la que hablaron tantos filósofos libertarios del siglo XX - en el lugar más inesperado, en el seno de la función pública.

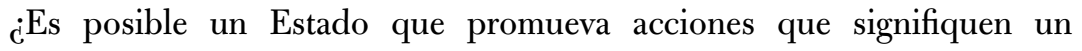
antagonismo con su propia condición de ser una expresión "constituida y atravesada por las luchas sociales"? Esta definición es parte de las teorías del Estado escrita por los estructuralistas post-althusserianos de la década del sesenta. Sobre ellas se levanta la persistente lógica hegeliana del Estado como "realidad de la idea moral", que en algunas de sus versiones avanzadas lleva a la tesis del Estado como forma última de la libertad (Eric Weil) y en otras lleva al entrecruce con el anarquismo que, como un soplo nada débil, cruza la obra de Lenin y desemboca en la tesis de la "extinción del Estado". Para postular hoy un Estado capaz de pensar la emancipación de la sociedad que lo constituye, es preciso dotarlo de formas internas paradójicas, de sectores del Estado "libertarios" que participan en la construcción colectiva de lo social con decisiones que también se autoinhiban.

¿Es extraño esto? No dejan de tomarse decisiones, pero no se deja pensar que ellas se resuelven, en cuanto a su brazo cultural, en una nueva forma de la libertad moderna. Si hay una estrategia en la vida cultural debe ser tácita, pues debe omitirse como tal cada vez que crea sus motivos más incisivos, pero en los 
demás ámbitos del Estado debe haber un agenciamiento de fuerzas sociales que puedan resolverse en su presencia en empresas productivas apartadas tanto de la reproductibilidad meramente capitalista como de la globalización compulsiva. De ahí que una política económica emancipada es, en el fondo, una verdadera política cultural; y una política cultural puede iniciar una época (incluso en la economía social), poniéndose en actitud crítica o denegatoria de las mismas instituciones públicas que le dieron origen. Parece difícil pero al fin esto es lo decisivo.

Aún resuenan las palabras de Benjamin Constant: "Entre los modernos, el individuo, independiente en la vida privada, aun en los Estados más libres, es sólo soberano en apariencia". Todo Estado moderno no solo tropieza con dificultades para erigirse en garante de la libertad sin caer en el liberalismo abstracto (donde impera la incultura del mercado) sino que su cometido más urgente es el de reconstruir la noción cultural de derechos individuales, sociales y colectivos. La creación de la reciente secretaría, a pesar de la poca fortuna de su nombre, debería cargar sobre sí la responsabilidad de hablar sobre las corrientes intelectuales del país en su más amplia acepción (y organizar conversaciones libres, foros de crítica y polemismo avanzado). Pero, ¿no hablan esas corrientes por sí mismas? Desde luego, y seguirán hablando cada vez más con autonomía del Estado que, sin embargo, ahora también habla institucionalmente sobre ellas. ¿Cómo debe hacerlo, puesto que el Estado, como todo Estado, es un Estado pensante? Con intervenciones propicias, capaces de negarse oportunamente a sí mismas, sabiendo que poseen un poder que saben y deben —llegado el caso - retirar de sí.

Muchas veces se dan pasos importantes con nombres y definiciones desventajosas. El error en el nombre podría auspiciar - ya ha auspiciado en las declaraciones de Forster sobre su formación de intelectual vinculado con las culturas críticas - un conjunto de actos impensables si no se hubiera partido de un concepto discordante que originó tremendas e injustas acusaciones. El pensamiento nacional descubre súbitamente que pertenece al orbe infinito de los grandes legados universales. Ese es el favorable resultado de tanto ensañamiento. El nombre descaminado puede ayudar a encontrar un camino. 